\title{
Role of ocular involvement in the prediction of visual development and clinical prognosis in Aicardi syndrome
}

\author{
Allison V Menezes, Terri L Lewis, J Raymond Buncic
}

\begin{abstract}
Aims/background-This study was undertaken to document visual function and acuity in patients with Aicardi syndrome, and to determine whether there is any relation between ocular features of the syndrome exhibited at birth and later visual function.

Methods-Fourteen patients with Aicardi syndrome, all examined and followed by the same ophthalmologist, were reviewed between 1975 and 1992 and their ocular characteristics and visual acuity described. It was hypothesised that larger lacunae may be associated with poorer clinical outcome and therefore the relation between these two variables was investigated.
\end{abstract}

Results-Visual acuity as documented by Snellen, Sheridan-Gardner, preferential looking, or pattern visual evoked potential tests was in the normal to low normal range in six eyes of four patients. Visual function correlated significantly with macular appearance. Good visual function was preserved if the fovea appeared normal on funduscopic examination and was uninvolved by lacunae. The size of the largest chorioretinal lacuna also correlated significantly with clinical outcome: patients with large lacunae were more likely to be immobile and to have no language skills.

Conclusion-It was concluded that good visual function in patients with Aicardi syndrome may be anticipated if the fovea is normal. Although many patients have severe psychomotor retardation, the presence of predominantly small chorioretinal lacunae may indicate a better prognosis for mobility and language development. (Br f Ophthalmol 1996;80:805-811)

Department of Ophthalmology, The Hospital for Sick

Children, Toronto, Canada

A V Menezes

T L Lewis

J R Buncic

Correspondence to:

Allison V M Menezes, MD Kantor Eye Institute, 2111 Bee Ridge Road, Sarasota, FL 34239, USA. syndrome have occurred in female patient karyotype and male phenotype. ${ }^{3}$ Skeletal malformations, especially costovertebral anomalies and scoliosis, are the most common malformations outside the central nervous system.
The cause of Aicardi syndrome is still unclear, although most authors ${ }^{45}$ agree that it is probably an $\mathrm{X}$ linked dominant disorder with early embryonic mortality in males and that each case represents a new mutation. The apparent ocular, cerebral, and skeletal abnormalities imply an insult to development between the fourth and seventh week of gestation..$^{6-8}$

Most clinical and ocular features of Aicardi syndrome have been described in the literature. Chevrie and Aicardi ${ }^{2}$ have provided a thorough update of the syndrome in their review of 38 patients examined by them and 146 others. All other reports ${ }^{6-10}$ describing ocular involvement have been literature reviews or case reports in which fewer than eight patients were examined by the same ophthalmologist. Such examinations by different ophthalmologists introduce interobserver variability in the description of ocular findings. Furthermore, although the ocular features of the syndrome have been described, visual acuity has not been documented by standard tests, nor has any correlation between the severity of ocular findings and functional changes been evaluated.

The most characteristic of these ocular findings is the chorioretinal lacunae, which do not change in size and number over time. ${ }^{2}$ They are multiple whitish or yellowish, non-elevated lesions with variable pigmentation at their borders. Although they usually cluster around the posterior pole, they can be present in the periphery, and their size varies from 0.1 to more than 3 disc diameters. ${ }^{69}$

Optic disc anomalies, particularly colobomas, are common; overall, some anomaly is reported in approximately $50 \%$ of patients. ${ }^{29}$ Other ocular abnormalities described in patients with Aicardi syndrome include microphthalmos, optic nerve hypoplasia, pupil membrane remnants, iris colobomas, choroidal colobomas, retinal detachment, and abnormal foveal development.

Visual evoked potential (VEP) and electroretinography (ERG) responses for patients with Aicardi syndrome have been reported infrequently. In one study, flash VEP elicited normal responses in five patients and no response in one other patient. ${ }^{11}$ ERG responses have been reported as normal in at least eight patients, ${ }^{212}$ decreased in amplitude in one, ${ }^{13}$ and extinguished in a microphthalmic eye of another patient. ${ }^{10}$ 
The few available reports that describe the prognosis for the cognitive and motor skills of patients with Aicardi syndrome indicate that the prognosis is significantly limited. Severe mental retardation is common $^{24}$; some language function has been documented in $6 \%-14 \%$ of patients. ${ }^{45}$ Similarly, only $6 \%-$ $15 \%$ of patients are able to walk. ${ }^{45}$ On the other hand, available qualitative information about their visual acuity suggests that the visual prognosis is better. Case reports ${ }^{69}$ of eight patients showed that half of the patients could fixate on a bright object and follow a bright light. However, of the four patients who could not fix and follow, only one had a specific ocular feature (bilateral microphthalmos) that could account for significant visual impairment.

This study was undertaken to document visual function and acuity in patients with Aicardi syndrome, and to determine whether there is any relation between ocular features of the syndrome exhibited at birth and later visual function. Furthermore, we hypothesised that larger lacunae may be associated with poorer clinical outcome and therefore investigated the relation between these two variables.

\section{Patients and methods}

Our study sample consisted of all patients with Aicardi syndrome seen at a local hospital between 1975 and 1992. All of these 14 girls had the diagnostic criteria for Aicardi syndrome: agenesis of the corpus callosum, infantile seizures, and pathognomonic chorioretinal lacunae. The extent of corpus callosum agenesis was assessed by pneumoencephalography, computed tomography scan, or magnetic resonance imaging depending on the best imaging procedure that was available at the time of diagnosis. All ocular examinations were performed by the third author. Thirteen of the patients were examined at less than 1 year of age, and their anterior segment examination, cycloplegic refraction, and funduscopic examination were documented. The remaining patient (patient $\mathrm{K}$, see Table 1 ) had a seizure disorder and was not diagnosed with Aicardi syndrome until her ophthalmic examination at 11 years of age. Photographs of the fundus were also obtained for 13 of the 14 girls.

We reviewed all fundus photographs and charts in 1992 and documented the ocular findings. Ocular features at birth and the status of the corpus callosum remain constant throughout life in patients with Aicardi syndrome. ${ }^{2}$ Lacunar size, estimated in disc diameters, was compared with the size of a clinically normal optic disc. The presence or absence of lacunae at the fovea was noted. In addition, the degree of foveal development was graded as good if a normal foveal pit with a healthy nerve fibre layer was present and poor if these features were absent or if a macular lacuna involved the fovea. Optic disc abnormalities were described as hypoplastic if the disc appeared smaller than normal, as colobomatous if a large excavation of the disc was present, and as dysmorphic if any other anatomical abnormality was present. Discs with only mildly anomalous vessels were classified as normal. Microphthalmos was defined clinically as a small eye with corneal diameter less that $10 \mathrm{~mm}$.

Flash VEP and ERG had been documented in five patients between the ages of 8 months and 7 years. ERG responses were recorded binocularly in three girls using a single red flash with skin electrodes. Bright flash VEP responses were also documented binocularly in three girls.

We contacted the families of all nine patients who were still alive in 1992 to determine the girls' level of function and to offer the families the opportunity to have their children's current visual acuity documented. We were able to document visual acuity quantitatively in only six of these patients because they currently live all across Canada. Although it would have been optimal to use the same method of evaluating visual acuity in all patients, this was not possible. Instead, we used the most rigorous visual acuity test available, depending on the limitations of patients' cognitive and motor skills. We used the standard Snellen method for each eye of one patient, the Sheridan-Gardner single letter test for each eye of another patient, pattern VEPs in each eye of two patients, and preferential looking techniques for five eyes of three patients. We used parental reports or clinical assessment to document visual function qualitatively in the remaining three patients who were still alive.

Pattern VEPs and preferential looking are now established methods for estimating visual acuity in non-verbal subjects. Details of the procedures we used for each test are provided elsewhere. ${ }^{14}{ }^{15}$ Each of these tests was performed by teams of trained observers at the hospital. Briefly, acuity was assessed with pattern VEPs by recording monocular responses to pattern reversing checkerboards and determining the smallest checks that elicited a response different from that elicited by a plain grey field. Acuity was assessed with preferential looking by determining the narrowest stripes that the child systematically chose over a plain grey stimulus $75 \%$ of the time.

Visual function for seven of the nine patients who were still alive in 1992 was compared with the clinical appearance of the macula and fovea. Patients $\mathrm{H}$ and J were excluded since the state of their foveae was unknown. We also excluded the right eye of patient $\mathrm{N}$ because of total retinal detachment. For the remaining 13 eyes, we used a three point scale to assign a visual function score and to assign a macular appearance score. Visual function was graded as 1 if acuity was 2 or more octaves (an octave is a halving or a doubling of a value) below normal for a given test at a given age, or if the child was visually inattentive, as observed by the parents. Grade 2 indicated visual function that was 1 octave below normal. Grade 3 described a child whose visual acuity was normal or low normal, or who was able to fixate on and follow an object, as observed by parents or found by clinical examination. For example, the visual function of a 9-month-old patient 
Table 1 Clinical features of 14 patients with Aicardi syndrome

\begin{tabular}{|c|c|c|c|c|c|c|c|c|c|c|}
\hline \multirow[b]{2}{*}{ Patient } & \multirow[b]{2}{*}{ Eye } & \multicolumn{3}{|c|}{ Ocular features at birth } & \multicolumn{2}{|l|}{ Abnormalities } & \multicolumn{2}{|c|}{ Visual function } & \multicolumn{2}{|c|}{$\begin{array}{l}\text { Outcome }(1992 \text { or } \\
\text { before death })^{*}\end{array}$} \\
\hline & & $\begin{array}{l}\text { Lacunae } \\
\text { involve } \\
\text { maculat }\end{array}$ & $\begin{array}{l}\text { Good } \\
\text { foveal } \\
\text { development }\end{array}$ & $\begin{array}{l}\text { Largest } \\
\text { lacuna } \\
\text { (DD) }\end{array}$ & Optic disc & Other ocular & Age tested & Result & $\begin{array}{l}\text { Age } \\
\text { (years) }\end{array}$ & Score \\
\hline \multicolumn{11}{|c|}{ Non-survivors: } \\
\hline A & $\begin{array}{l}\mathbf{R} \\
\mathbf{L}\end{array}$ & + & + & $\begin{array}{l}0.5-1 \\
0.5-1\end{array}$ & $\begin{array}{l}\text { H, D } \\
\text { C, D }\end{array}$ & & & & 1 & 1 \\
\hline \multirow[t]{2}{*}{ B } & $\overrightarrow{\mathbf{R}}$ & $+(\mathbf{F}) \ddagger$ & - & $>5$ & $\mathrm{C}$ & $\begin{array}{l}\text { C (retinal), } \\
\text { Microph }\end{array}$ & & & 2 & 1 \\
\hline & L & $+(F)$ & - & $>5$ & Pigmented & & & & & \\
\hline C & $\begin{array}{l}\mathbf{R} \\
\mathbf{L}\end{array}$ & $+(F)$ & $\begin{array}{l}- \\
-\end{array}$ & $\begin{array}{l}1-5 \\
1-5\end{array}$ & $\begin{array}{l}\text { Pigmented } \\
\text { Pigmented }\end{array}$ & Microph, R/D & & & 3 & 1 \\
\hline D & $\begin{array}{l}\bar{R} \\
\mathbf{L}\end{array}$ & $\begin{array}{l}+ \\
- \\
\end{array}$ & $\overline{+}$ & $\begin{array}{l}>5 \\
1-5\end{array}$ & $\begin{array}{l}\mathrm{D} \\
\mathrm{H}, \mathrm{D}\end{array}$ & & & & 13 & 1 \\
\hline E & $\begin{array}{l}\bar{R} \\
\mathbf{L}\end{array}$ & $\begin{array}{l}+(F) \\
-\end{array}$ & $\begin{array}{l}- \\
-\end{array}$ & $\begin{array}{l}>5 \\
1-5\end{array}$ & $\begin{array}{l}\mathrm{D} \\
\mathrm{H}, \mathrm{D}\end{array}$ & Microph, XT & & & 14 & 1 \\
\hline \multicolumn{11}{|c|}{ Survivors: } \\
\hline F & $\begin{array}{l}\text { R } \\
\text { L } \\
\text { Both }\end{array}$ & $\overline{+}(\mathrm{F})$ & - & $\begin{array}{l}0.5-1 \\
1.5\end{array}$ & $\begin{array}{l}\text { H, D } \\
\text { H, D }\end{array}$ & & $\begin{array}{l}9 \text { months } \\
9 \text { months } \\
8 \text { months }\end{array}$ & $\begin{array}{l}24 \operatorname{arc} \min \oint \\
24 \operatorname{arc} \min \S \\
\operatorname{VEP}(\mathrm{N}), \text { ERG }(\mathrm{N})\end{array}$ & 2 & 1 \\
\hline \multirow[t]{2}{*}{ G } & $\mathbf{R}$ & - & + & $1-5$ & Drusen & & $\begin{array}{l}1 \text { year } \\
2 \text { years }\end{array}$ & $\begin{array}{l}7.5 \operatorname{arcmin}(N) \\
5 \operatorname{arc} \min (\mathrm{N}) \circlearrowleft\end{array}$ & 3 & 3 \\
\hline & $\mathbf{L}$ & - & + & None seen & Drusen & & $\begin{array}{l}1 \text { year } \\
2 \text { years }\end{array}$ & $\begin{array}{l}7.5 \operatorname{arc} \min (N) \\
4 \operatorname{arc} \min (N) \int\end{array}$ & & \\
\hline \multirow[t]{2}{*}{ I } & $\begin{array}{l}\mathrm{R} \\
\mathrm{L}\end{array}$ & $\begin{array}{l}- \\
-\end{array}$ & $\begin{array}{l}+ \\
+\end{array}$ & $\begin{array}{l}\text { None seen } \\
0.5-1\end{array}$ & $\begin{array}{l}\mathbf{N} \\
\mathrm{H} \\
\mathrm{D}\end{array}$ & Post embryotoxon & 3 years & $\begin{array}{l}20 / 30(N)^{\star \star} \\
20 / 30(N)^{\star \star}\end{array}$ & 5 & 4 \\
\hline & Both & & & & & & 1 year & $\operatorname{VEP}(\mathrm{N})$ & & \\
\hline J & $\begin{array}{c}\text { R } \\
\text { L } \\
\text { Both }\end{array}$ & $\begin{array}{l}- \\
-\end{array}$ & & $\begin{array}{l}1-5 \\
\text { None seen }\end{array}$ & $\begin{array}{l}\text { Pigmented } \\
\text { Pigmented }\end{array}$ & & $\begin{array}{l}8 \text { years } \\
8 \text { years } \\
3 \text { years }\end{array}$ & $\begin{array}{l}\text { Inattentive } \\
\text { Inattentive } \\
\text { VEP, ERG (N) }\end{array}$ & 8 & 1 \\
\hline $\mathrm{K}$ & $\begin{array}{l}\mathbf{R} \\
\mathbf{L}\end{array}$ & $\begin{array}{l}- \\
-\end{array}$ & $\begin{array}{l}+ \\
+\end{array}$ & $\begin{array}{l}<0.5 \\
0.5-1\end{array}$ & $\begin{array}{l}\mathrm{N} \\
\text { Anom } \\
\text { vessels }\end{array}$ & Anisometropia & 11 years & $\begin{array}{l}20 / 400+\mathrm{tt} \\
20 / 25(\mathrm{~N}) \mathrm{Ht}\end{array}$ & 12 & 4 \\
\hline L & $\begin{array}{l}\text { R } \\
\text { L } \\
\text { Both }\end{array}$ & $\begin{array}{l}- \\
-\end{array}$ & $\overline{-}$ & $\begin{array}{l}>5 \\
0.5-1\end{array}$ & $\begin{array}{l}\mathrm{H}, \mathrm{D} \\
\mathrm{H}\end{array}$ & & 7 years & $\begin{array}{l}15 \text { arc } \min \\
30 \text { arc min } \\
\text { ERG }(N)\end{array}$ & 14 & 1 \\
\hline $\mathbf{M}$ & $\begin{array}{l}\mathbf{R} \\
\mathbf{L}\end{array}$ & $\begin{array}{l}- \\
-\end{array}$ & $\begin{array}{l}+ \\
+\end{array}$ & $\begin{array}{l}>0.5-1 \\
>5\end{array}$ & $\begin{array}{l}\mathrm{H} \\
\mathrm{D}\end{array}$ & & 16 years & $\begin{array}{l}\text { Fix and follow } \neq \ddagger \\
\text { Fix and follow } \neq \ddagger\end{array}$ & 16 & 1 \\
\hline $\mathbf{N}$ & $\begin{array}{l}\mathbf{R} \\
\mathbf{L}\end{array}$ & - & + & $\begin{array}{l}>5 \\
>5\end{array}$ & $\begin{array}{l}\text { D } \\
\text { H, D }\end{array}$ & Microph, R/D & 19 years & $\begin{array}{l}\text { Untestable } \\
1.5 \text { arc min }(N) \oint\end{array}$ & 20 & 1 \\
\hline
\end{tabular}

$\mathrm{H}=$ hypoplastic $\mathrm{D}=$ dysplastic; $\mathrm{C}=$ colobomatous; Microph = microphthalmos; $\mathrm{R} \mathrm{D}=$ retinal detachment; $\mathrm{XT}=$ exotropia; dvpt $=$ development; $\mathrm{VEP}=$ visual evoked potential; $\mathrm{N}=$ normal; $\mathrm{ERG}=$ electroretinography response; Post $=$ posterior; Anom $=$ anomalous.

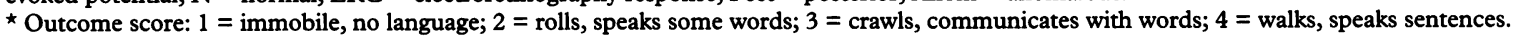

$t+=$ yes; $-=$ no; $(F)=$ and fovea.

$\ddagger$ Lacunae also involve fovea.

$\$$ Preferential looking acuity.

Pattern visual evoked potential acuity.

If Estimation of visual function by parental observation.

$\star \star$ Sheridan-Gardner visual acuity test.

tt Snellen visual acuity.

¥ Estimation of visual function by clinical examination.

who obtained a value of 24 arc minutes on tests of preferential looking acuity would be grade 2 because 24 arc minutes is approximately 1 octave below the normal limit of 13 arc minutes for this test and this age group. ${ }^{15}$ Similarly, the visual function of a 1-year-old patient who obtained a value of 7.5 arc minutes on tests of pattern VEP acuity would be graded as 3 because 7.5 arc minutes is within normal limits for this test and this age group. ${ }^{15}$

Macular appearance was classified as grade 1 if the fovea was involved by lacunae and thus poorly developed. Grade 2 indicated either poor foveal development or macular, but not foveal, lacunae. Grade 3 indicated good foveal development with no macular lacunae.

Clinical outcome measures were defined by mobility and language function and documented up to 1992 or before death. We chose the degree of mobility and language function as measures of clinical outcome on the basis of a study by Eyman et al. ${ }^{16}$ In a review of over 7000 individuals who had severe deficits in cognitive function, Eyman and associates showed that severe mental retardation is associated with decreased life expectancy, particularly for those who are immobile.

Since mobility corresponded perfectly with language skills, clinical outcome was classified on a four point scale: 1 represented immobility and no language; 2 the ability to roll and to speak some intelligible words; 3 the ability to crawl and communicate with words; 4 the ability to walk and speak in sentences. The Spearman rank order correlation was used to evaluate the relation between visual function and macular appearance. The probability of a statistically significant relation was assessed by determining the $p$ value of the Spearman rank order correlation coefficient (rho). A similar rank order correlation test was performed to evaluate the relation between the size of the largest chorioretinal lacuna in a given patient and that patient's clinical outcome score.

\section{Results}

Table 1 describes the clinical findings for all 14 patients. All patients had chorioretinal lacunae 


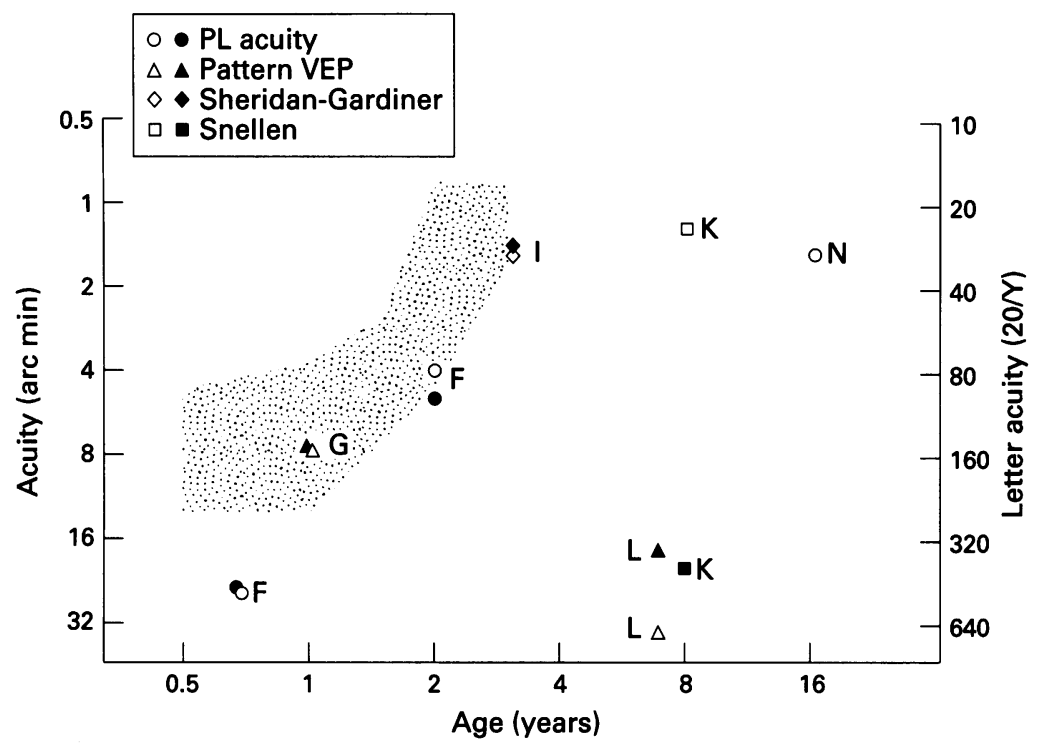

Figure 1 Visual acuity as a function of age at test in six patients with Aicardi syndrome. The right vertical axis shows the denominator $(Y)$ of the Snellen fraction in feet. Each point gives the acuity for one eye as measured by preferential looking (PL), pattern visual evoked potentials (VEP), the Sheridan-Gardiner single letter test, or the Snellen test. Filled symbols represent data for the right eye and open symbols, data for the left eye. Letters adjacent to each symbol refer to the patients described more fully in Table 1. The shaded area shows the range of values obtained from normal children tested monocularly with preferential looking (see Lewis and Maurer ${ }^{15}$ ). For pattern VEPs, values of at least 7.5 arc minutes are within normal limits after 6 months of age. ${ }^{15}$

that were characteristic of Aicardi syndrome: lacunar size ranged from less than 0.5 disc diameters to greater than 5 disc diameters. They often clustered around the posterior pole, although large lacunae were sometimes seen in the mid periphery. Monocular lacunae were present in three $(21 \%)$ of the 14 girls, of whom two (patients $G$ and $I$ ) had good visual acuity in each eye and one (patient $J$ ) was visually inattentive with abnormal flash VEPs.

Some optic disc abnormality was found in 26 of 28 eyes. Eight (57\%) girls had dysmorphic discs, three $(21 \%)$ had colobomas, which were unilateral in this series, and eight $(57 \%)$ had mild or moderate optic nerve hypoplasia. None of the optic discs was severely hypoplastic. No simple optic nerve atrophy was found.

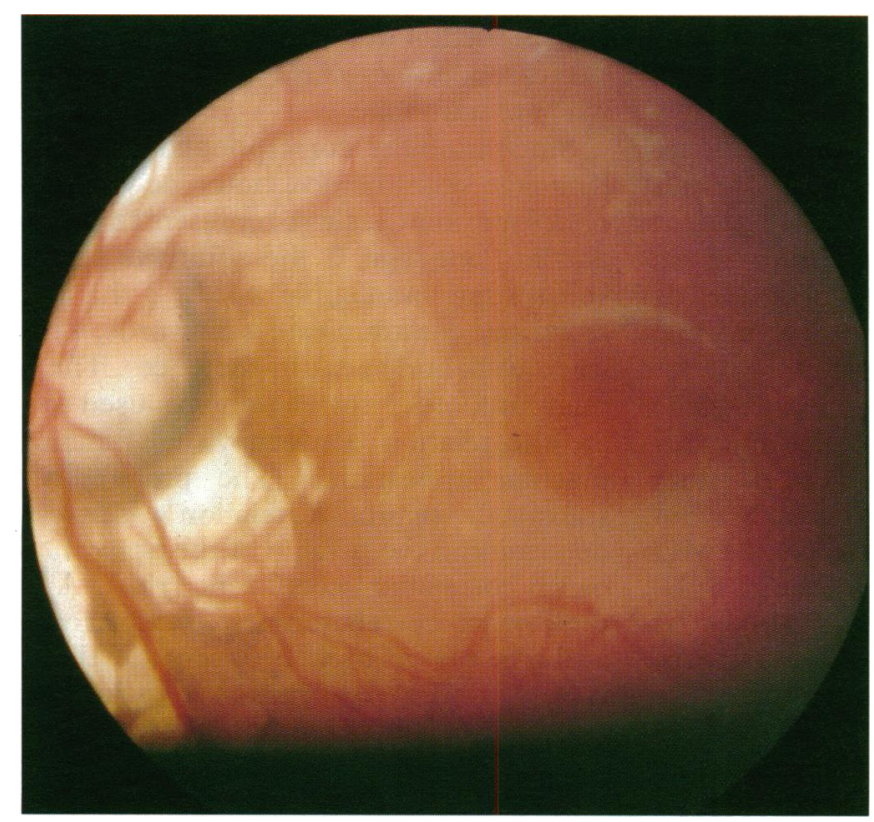

Figure 2. Photograph of the fundus of the left eye of patient $N$ showing typical chorioretinal lacunae that spare the macula.
Severe ocular abnormalities were present in four patients (patients B, C, E, and N). These patients were also immobile. These four girls had unilateral microphthalmos; the retina in two of these eyes was detached. One girl (patient $\mathrm{N}$ ) had good visual acuity with the other eye. The other three girls did not survive. Although no information about their visual function is available, their foveae were all poorly developed.

Visual function in the nine patients who survived is also described in Table 1. For six of these nine patients (that is, patients $F, G, I, K$, $L, N$ ), we obtained quantitative estimates of visual acuity and their results are illustrated in Figure 1. Visual acuity was in the normal to low normal range in both eyes of patient $G$, whether tested with preferential looking or pattern VEP, and in both eyes of patient I. Visual acuity was also normal in one eye of each of two additional patients (patients $K$ and $N$ ). None of these six eyes demonstrated lacunae involving the fovea; all had a normal appearing fovea (Fig 2).

Three of the six patients (patients $F, K$, and L) had visual acuity results below normal in at least one eye. Right anisometropic amblyopia was probably the basis of the poor visual acuity in the right eye of patient $K$.

For the remaining four of the nine patients who were still alive in 1992, visual function was estimated qualitatively from parental reports or clinical examination. Two of these patients (patients $\mathrm{H}$ and $\mathrm{M}$ ) were able to fixate on and follow an object. The foveae of patient $M$ were normal, but the state of foveal development of patient $\mathrm{H}$ could not be determined from available photographs of the fundus. Patient $\mathrm{J}$ was visually inattentive. Although her chart review indicated that the maculae were uninvolved with lacunae, the development of her foveae could not be adequately determined from photographs of the fundus. Finally, the right eye of patient $\mathrm{N}$ was assumed to have no visual function: the retina was totally detached and preferential looking acuity tests could not be used because the eye remained closed when the left eye was patched.

Figure 3 summarises the relation between the visual function score and the macular appearance score for the 13 eyes that could be classified on both measures. As shown in Figure 3, all but three eyes (the right eye of patient $F$, the right eye of patient $K$, and the left eye of patient L) showed a perfect correspondence between the visual function score and the macular appearance score. A Spearman rank order correlation for all 13 eyes confirmed a significant relation between these two variables (rho $=0.72, p<0.01$ ), indicating that good foveal development is associated with good visual function in Aicardi syndrome.

Flash ERG or flash VEP responses were measured in four of the nine surviving patients. Flash ERGs were normal in all three patients tested. However, all three had abnormal visual function as assessed by preferential looking (patient F), pattern VEPs (patient L), or parental observation (patient $J$ ). 


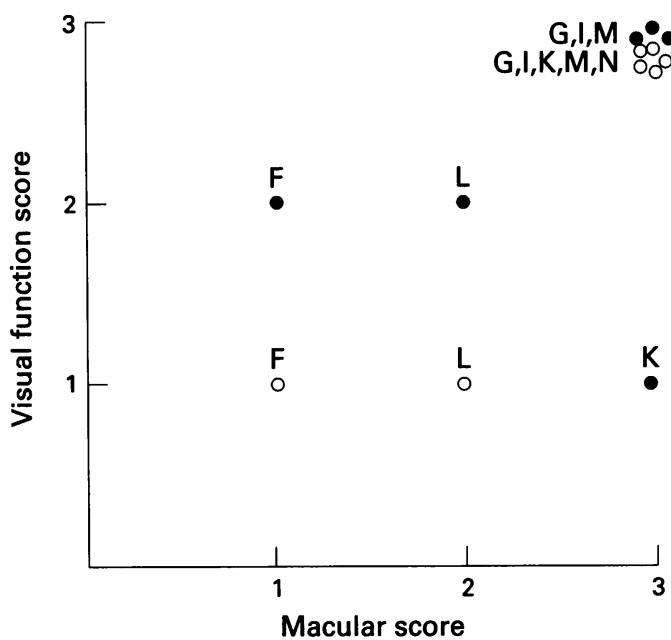

Figure 3 The relation between visual function and macular appearance in 13 eyes of seven patients that could be classified on both measures. Higher values represent better scores (see text for details). Filled circles represent the right eye and open circles represent the left eye. Letters identify the patients listed in Table 1.

Flash VEPs were abnormal in one patient (patient J), a finding that was consistent with parental reports of visual inattentiveness. Moreover, flash VEPs were normal in a second patient (patient I) who had normal acuity measured on the Sheridan-Gardner test. However, they were also normal in the third patient (patient F) who had abnormal preferential looking acuity.

A poor clinical outcome was evident in 10 $(71 \%)$ of 14 patients (Table 1 ): these 10 were immobile and had no language skills (that is, a clinical outcome score of 1 ). All five patients who died fell into this category before death. Of the nine patients who were alive, five had a poor outcome score of 1 (patients $F, J, L, M$, and $N$ ). Good visual function, evaluated either subjectively by parents or objectively, was found in all four of the girls who could ambulate. However, two of those who were immobile (patients $M$ and $N$ ) also had good visual function.

Figure 4 shows the relation between clinical outcome score and the size of the largest lacuna at birth. The six patients (patients $B, D$, $\mathrm{E}, \mathrm{L}, \mathrm{M}$, and $\mathrm{N}$ ) with the largest lacunae (5 disc diameters) also had the worst clinical outcome score. Moreover, the two patients (patients I and $\mathrm{K}$ ) with the best clinical outcome scores also had the smallest lacunae. A Spearman rank order correlation for all 14 patients revealed a moderate but significant correlation between lacunar size and outcome score $(\mathrm{rho}=0.63, \mathrm{p}<0.02)$.

We also considered the association between the neuroradiological findings at time of diagnosis of Aicardi syndrome and the ultimate clinical outcome. All our patients demonstrated partial (patients $G, K$, and $M$ ) or total agenesis of the corpus callosum either on pneumoencephalography (patients $\mathrm{E}, \mathrm{D}$, and $M$ ), computed tomography scanning (patients $A, B, C, F, G, H, I, J, L$, and N), or magnetic resonance imaging (patient $\mathrm{K}$ ). Although all three of the girls with partial agenesis had good visual function, two were able to ambulate and

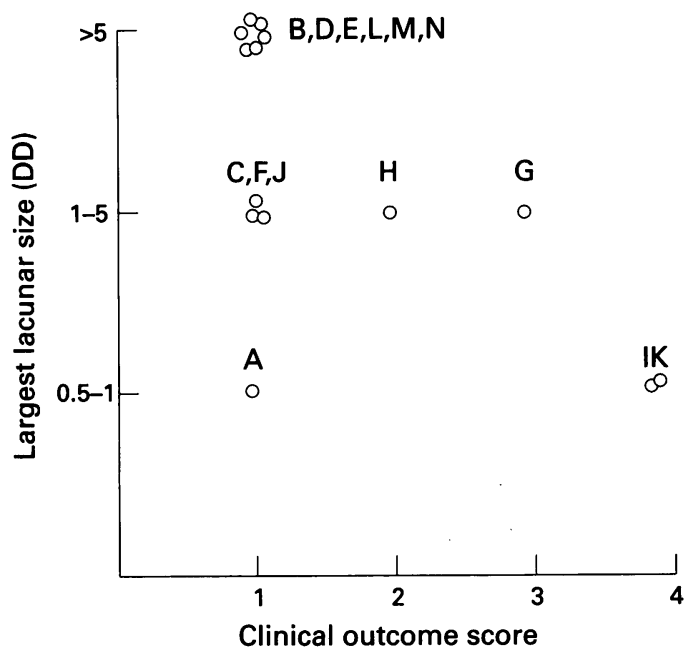

Figure 4 The relation between the largest lacunar size and clinical outcome for all 14 patients in our series. Each point represents the results for one patient. Higher values on the $X$ axis represent a better clinical outcome score (see text for details). Letters adjacent to each point identify the patients listed in Table 1.

communicate; one was not. Other neuroradiological abnormalities included porencephalic cysts (patients $D, G, I$, and J), decreased cortical tissue (patients $B, C, D, F, M$, and $N$ ), and cortical heterotopias (patients $\mathrm{B}, \mathrm{D}$, and I). Of the three girls with heterotopias, two have died (at age 13 years and 2 years); one can walk and speak, and has normal visual acuity on Sheridan-Gardner single letter testing.

\section{Discussion}

We have described the ocular findings, visual function, and clinical outcome, as measured by mobility and language, in a series of 14 patients with Aicardi syndrome. We found that the degree of ocular involvement at birth can suggest the child's visual, language, and ambulatory potential. Specifically, good visual function can be expected if the chorioretinal lacunae do not involve the fovea and if normal foveal development is apparent on clinical examination. Children with smaller chorioretinal lacunae at birth appear to have a better ultimate clinical prognosis: they have better mobility and language skills. Since the location and size of the chorioretinal lacunae do not change during the patient's lifetime, their status can be evaluated at any time to assist in determining the patient's visual and clinical prognosis.

Visual development can sometimes be estimated by flash ERGs or flash VEPs. Other authors ${ }^{21-13}$ have found normal responses in most patients tested with flash VEP or ERG. They did not, however, make any attempt to correlate these findings with more rigorous methods of testing visual acuity. In our series, neither flash VEP nor flash ERG recorded before visual acuity testing was useful in predicting ultimate visual function in patients with Aicardi syndrome.

Good visual function appears to be preserved, as expected, if the chorioretinal lacunae do not involve the fovea and if the foveal development appears normal on funduscopic examination. Previous histopathological stud- 
ies $^{7}$ of the chorioretinal lacunae show hypopigmentation and abnormal differentiation of the retinal pigment epithelium, as well as a disorganised sensory retina. Thus, poor visual function should be anticipated when lacunae involve the fovea, and good visual function when the lacunae do not involve a well differentiated fovea. Our findings of a significant correlation between visual function and macular appearance confirmed this prediction.

Although good visual outcome may be suggested by a normal appearing fovea devoid of lacunae, other factors may play an important role in visual development. Ocular abnormalities such as retinal detachment and anisometropia contributed to poor vision in our patients. Even if the anterior visual pathways appear intact, the posterior pathways, which are important in processing and interpreting visual signals, may be abnormal. These posterior pathways may be affected by sedation secondary to anticonvulsants, seizure activity, or neuroanatomical abnormalities. Neuroradiological studies ${ }^{28}$ of patients with Aicardi syndrome have illustrated such abnormalities as partial or total agenesis of the corpus callosum, cortical heterotopias (resulting from abnormal neuronal migration), ventricular dilatation, porencephaly, posterior fossa cysts, and cerebellar hypoplasia. In addition, abnormalities in cortical cytoarchitecture, malformations of cerebral gyri, and agenesis of the corpus callosum have been confirmed histopathologically. ${ }^{217-19}$ Despite the evidence of large brain lesions, however, no optic atrophy that could have resulted from such abnormalities was identified.

Partial agenesis of the corpus callosum may be associated with good vision, since all three of our patients had good visual function. However, partial agenesis of the corpus callosum does not necessarily predict good clinical outcome: only two of these three patients were mobile. Cortical heterotopias, surprisingly, did not predict either visual or clinical outcome. Of the three patients with heterotopias, two were immobile and had no language before death, but one had normal visual acuity and was able to walk and speak. Note, however, that had our sample been larger, we might have found a significant relation between the status of the central nervous system and clinical outcome.

Since patients with Aicardi syndrome are often developmentally delayed, clinical measurements of visual acuity may also be affected by their mental retardation and lack of cooperation. On ophthalmic examination, developmentally delayed children who are over the age of 30 months and have normal eyes have been shown to have below normal preferential looking grating acuities (Wyngaarden and Lewis, unpublished data). Under that age, however, Wyngaarden and colleagues (unpublished data) found no relation between cognitive level and grating acuity. This suggests that our 19-year-old patient $\mathrm{N}$, whose grating acuity in her left eye was in the low normal range, might have visual acuity well within normal limits if her marked developmental delay were not present. In contrast, there would be no reason to expect that developmental delay contributed to the poor grating acuity of patient $F$, tested at 9 months of age. Nor would there be any reason to believe that developmental delay affected the objective pattern VEP results.

Good visual function does not consistently predict a better clinical outcome. Four girls who had good vision in at least one eye all had some ambulatory and language skills. However, two patients who were immobile and had no language ability still demonstrated good visual function in at least one eye.

When we evaluated the size, location, and symmetry of the lacunae to determine whether these factors could predict eventual clinical outcome, we found that the size of the largest chorioretinal lacuna was moderately but significantly correlated with outcome measures of mobility and language skills. All patients whose lacunae were larger than 5 disc diameters in at least one eye were immobile. Furthermore, of the four patients who had a good clinical outcome, one was only mildly affected in both eyes, and the other three had asymmetric ocular involvement with small or no lacunae in one good eye. Despite the potential inaccuracy of sizing the lacunae by gross visual comparison with a clinically normal optic disc, we were still able to show a significant correlation with mobility and language outcome. The size of the largest lacuna did not, however, appear to correlate with visual function. Rather, visual function correlated with the degree of foveal differentiation or involvement by the lacunae.

The chorioretinal lacunae can be asymmetric in size, as in two of our patients who had lacunae in one eye that were larger than 5 disc diameters and in the other eye, smaller than 1 disc diameter. Lacunae can also occur in only one eye: monocular lacunae have been described in $8 \%$ to $14 \%$ of patients in other reports. ${ }^{28}$ We found them in three $(21 \%)$ of our patients: two had good visual, ambulatory, and language development; one did not. Evidently, the presence of only monocular lacunae does not consistently predict clinical prognosis.

Severe eye disease was also asymmetric in our series. Microphthalmos, found in four $(29 \%)$ of our patients, was associated with retinal detachment in two and with a large retinal and iris coloboma in another. Microphthalmos has been reported in $21 \%-44 \%$ of patients. ${ }^{248}$ Although it is usually unilateral, it is difficult to determine from the available reviews whether the other eye was also severely involved. In our series, the other eye of the four patients with microphthalmos was of normal size with no retinal detachment. In fact, the normal sized eye of patient $\mathrm{N}$ had normal visual acuity, as measured by preferential looking. Three of the four patients with such severe eye disease died, one by age 14 years and two by age 3 years. The remaining girl who survived is immobile and has no language skills. Clearly, severe ocular involvement is often unilateral and appears to be an indicator of poor prognosis.

We found some optic nerve abnormality in at least one eye of all of our patients, although 
others have found a much lower frequency ( $50 \%$ of patients). ${ }^{29}$ This discrepancy probably reflects our inclusion criteria, since we, unlike others, classified optic nerve drusen and mildly hypoplastic, dysplastic, or pigmented discs as abnormal. Optic nerve abnormalities, however, do not seem to be associated with either impaired vision or poor clinical outcome. Despite the presence of dysmorphic, hypoplastic, or colobomatous discs in four of our patients, they all demonstrated good visual function as long as the foveal development in the affected eye was good. Of the nine patients still alive, six had significant disc abnormalities, a finding that illustrates the poor prognostic value of this feature.

In conclusion, the description and frequency of the ocular features in our series of patients with Aicardi syndrome are similar to those discussed by other authors, with the exception of the frequency of optic disc abnormalities. To our knowledge, however, this is the first systematic evaluation of visual acuity in patients with Aicardi syndrome and of the prognostic relation between ocular features at birth and clinical and visual outcome.

Our findings emphasise the role of the ophthalmologist both in the diagnosis and management of patients with Aicardi syndrome. The diagnosis can be confirmed from the identification of pathognomonic chorioretinal lacunae. Visual acuity can be documented with standard clinical tests such as the Snellen and Sheridan-Gardner tests, or with pattern VEP and preferential looking, if available. Unfortunately, in our series, the role of ERGs and VEPs with a flash stimulus had limited predictive value for estimating visual function. Good visual function can be anticipated if the fovea of at least one eye appears normally developed and is uninvolved by lacunae. The child should receive regular ophthalmic care and be monitored for anisometropia, refractive error, and retinal detachment. Severe involvement of one eye with microphthalmos may indicate a poor prognosis. All patients should receive maximal therapeutic assistance to enable them to develop to their full potential since this cannot be predicted with certainty in infancy. However, the presence of predominantly small chorioretinal lacunae, especially if one eye is normal or only mildly involved, suggests a bet- ter prognosis for mobility and language development in children with Aicardi syndrome.

This paper was prepared with the assistance of Editorial Services, The Hospital for Sick Children, Toronto, Ontario, Canada.

Presented in part as a poster at the Canadian Congress of Neurosciences, Toronto, Ontario, Canada, June 1993.

Supported in part by National Institutes of Health (Bethesda, MD) Grant EY-03475.

1 Aicardi J, Lefebvre J, Lerique-Koechlin A. A new syndrome: spasms in flexion, callosal agenesis, ocular abnormalities. Electroencephalogr Clin Neurophysiol 1965;19:609-10.

2 Chevrie JJ, Aicardi J. The Aicardi syndrome. In: Pedley TA Meldrum BS, eds. Recent advances in epilepsy, vol 3 . Edinburgh: Churchill Livingstone, 1986:189-210.

3 Hopkins IJ, Humphrey I, Keith CG, Susman M, Webb GC, Turner EK. The Aicardi syndrome in a 47, XXY male. Aust Paediatr f 1979;15:278-80.

4 Donnenfeld AE, Packer RJ, Zackai EH, Chee CM, Sellinger B, Emanuel BS. Clinical, cytogenetic, and pedigree findings in 18 cases of Aicardi syndrome. Am $\mathcal{F}$ Med Genet 1989;32:461-7.

5 Neidich JA, Nussbaum RL, Packer RJ. Heterogeneity of clinical severity and molecular lesions in Aicardi syndrome. $\mathcal{f}$ Pediatr 1990;116:911-7.

6 Hoyt CS, Billson F, Ouvrier R, Wise G. Ocular features of Aicardi's syndrome. Arch Ophthalmol 1978;96:291-5.

7 Del Pero RA, Mets MB, Tripathi RC, Torczynski E. Anomalies of retinal architecture in Aicardi syndrome. Anomalies of retinal architecture in

8 Brch Ophthalmol 1986;104:1659-64. report of 4 cases and review of the literature. Ann Neurol 1979;5:475-82.

9 Denslow GT, Robb RM. Aicardi's syndrome: a report of four cases and review of the literature. $\mathcal{F}$ Pediatr Ophthalmo Strabismus 1979;16:10-5.

10 Rousselie F, Fontaine $\mathbf{M}$. Anomalies chorio-retiniennes. Spasmes en flexion. Agenesie calleuse. Arch Opht (Paris) 1979;31(6-7):539-46.

11 Yamamoto N, Watanabe K, Negoro T, Matsumoto A, Hara K, Miyazaki S, et al. Aicardi syndrome. Report of 6 cases and a review of Japanese literature. Brain Dev 1985;7:443 9.

12 Weleber RG, Lovrien EW, Isom JB. Aicardi's syndromecase report, clinical features and electrophysiologic studies. Arch Ophthalmol 1978;96:285-90.

13 Gerhard JP, Juif JG, Luckel JC, Mack M. A propos d'une nouvelle observation de syndrome de spasme en flexion, agenesie calleuse et anomalies chorio-retiniennes (syndrome Aicardi). Bull Soc Ophtalmol Fr 1973;3:363-6.

14 McCulloch DL, Skarf B. Development of the human visual system: monocular and binocular pattern VEP latency. system: monocular and binocular pattern
Invest Ophthalmol Vis Sci 1991;32:2372-81.

15 Lewis TL, Maurer D. Preferential looking as a measure of Lewis $\mathrm{TL}$, Maurer $\mathrm{D}$. Preferential looking as a measure of
visual resolution in infants and toddlers: a comparison of psychological methods. Child Dev 1986;57:1062-75. (Experiment 3)

16 Eyman RK, Grossman HJ, Chaney RH, Call TL. The life expectancy of profoundly handicapped people with mental retardation. N Engl ₹ Med 1990;323:584-9.

17 deJong JGY, Delleman JW, Houben M, Manschot WA, de Minjer A, Moi J, et al Agenesis of the corpus callosum, infantile spasms, ocular anomalies (Aicardi's syndrome)clinical and pathologic findings. Neurology 1976;26:11528 .

18 Font RL, Marines HM, Cartwright J, Bauserman SC. Aicardi syndrome-a clinicopathologic case report including electron microscopic observations. Ophthalmology 1991;98:1727-31.

19 McMahon RG, Bell RA, Moore GRW, Ludwin SK Aicardi's syndrome. A clinicopathologic study. Arch Ophthalmol 1984;102:250-3. 